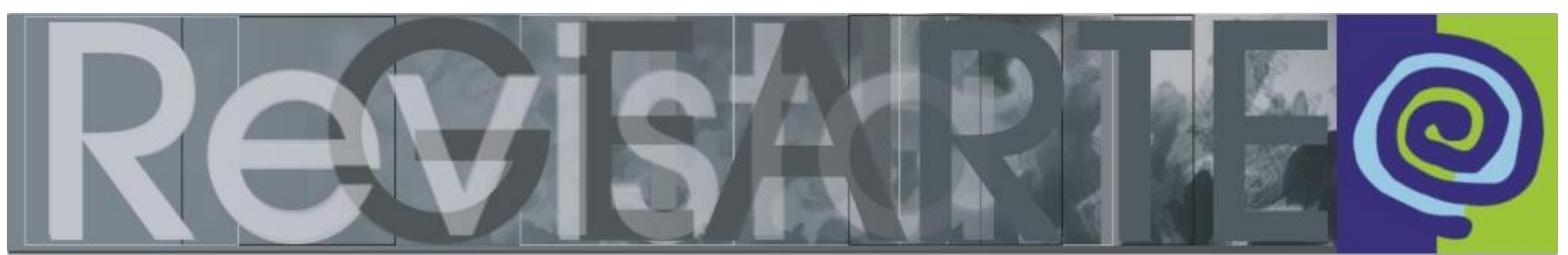

ISSN 2357-9854 | e-ISSN 2596-3198 (online)

\title{
Enseñanza-aprendizaje del dibujo. Una propuesta transdisciplinar que acoge el pensamiento complejo
}

\author{
Bernardo Bustamante Cardona \\ (Universidad de Antioquia — UdeA, Medellín, Colombia)
}

\begin{abstract}
RESUMEN - Enseñanza-aprendizaje del dibujo. Una propuesta transdisciplinar que acoge el pensamiento complejo - En el artículo, primero se define el concepto de complejidad y su relación con la pedagogía. Luego se plantean diversas tensiones entre enfoques y tendencias de la enseñanza del dibujo; estas tendencias funcionan como bucles de realimentación que permanecen o se desvanecen en el tiempo y que actúan a modo de códigos clásicos y de obstáculos metafísicos, sustancialistas, antropocéntricos y estructuralistas semióticos. Por último, se proponen algunas estrategias, operaciones y procedimientos en los cuales se puede basar la enseñanza del dibujo partiendo de lo transdisciplinar. Esto permite sustentar la tesis central relacionada con la necesidad de realizar un giro de paradigma que propone el pensamiento complejo como estrategia para la enseñanza del dibujo.
\end{abstract}

PALABRAS CLAVE

Enseñanza del dibujo. Complejidad. Transdisciplinariedad. Códigos y operaciones del dibujo.

\begin{abstract}
Drawing learning and teaching. A transdisciplinary proposal that embraces the complex thought - In this article, the concept of complexity is defined and its relationship with pedagogy is discussed. Afterwards, issues between different approaches and trends of drawing teaching are set out; It is considered that these drawing teaching trends work as feedback loop which stays or fades through the time. These loops work as classic codes and obstacles that are presented as metaphysical, substantialist and anthropocentric obstacles as well as structuralist semiotics. Finally, some strategies, operations and procedures are proposed as a basis of the drawing leaning starting from the trans disciplinary approach. This supports the thesis which tells that there is a need to change the existent paradigm for the complex thought one as a strategy to teach to draw.
\end{abstract}

\section{KEYWORDS}

Drawing teaching. Complexity. Transdisciplinarity. Drawing codes and operations.

RESUMO - Ensino-aprendizagem de desenho. Uma proposta transdisciplinar que acolhe o pensamento complexo - No artigo, num primeiro momento se define o conceito de complexidade e sua relação com a pedagogia. Em seguida, são apresentadas diversas tensões entre abordagens e tendências do ensino do desenho; essas tendências funcionam como ciclos de realimentação que permanecem ou se desvanecem no tempo e que atuam como códigos clássicos e obstáculos metafísicos, substancialistas, antropocêntricos e estruturalistas semióticos. Por último, são propostas algumas estratégias, operações e procedimentos nos quais se pode embasar o ensino do desenho partindo da transdisciplinaridade. Isso permite sustentar a tese central relacionada à necessidade de realizar uma mudança de paradigma que proponha o pensamento complexo como estratégia para o ensino do desenho.

\section{PALAVRAS-CHAVE}

Ensino do desenho. Complexidade. Transdisciplinaridade. Códigos e operações do desenho. 


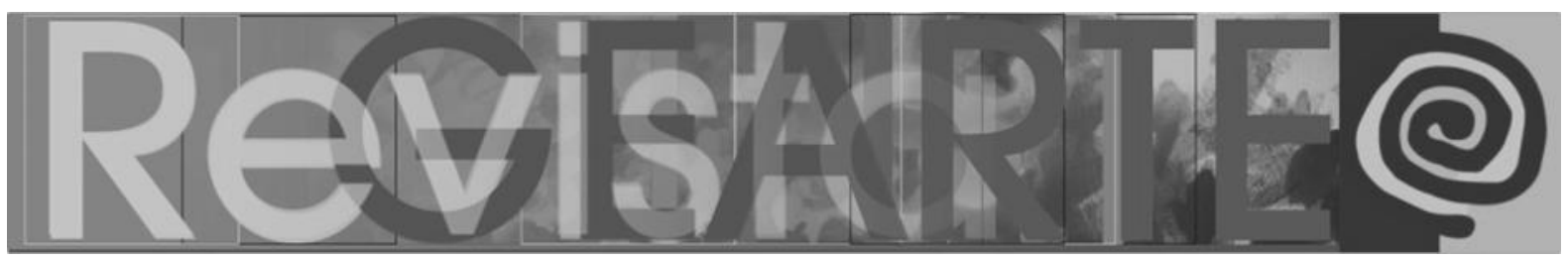

En todas las ficciones, cada vez que un hombre se enfrenta con diversas alternativas, opta por una y elimina las otras; en la del casi inextricable Ts'ui Pên, opta - simultaneamente - por todas. (BORGES, 1984).

\section{Introducción}

Este artículo da cuenta de una reflexión que parte de las prácticas docentes realizadas durante más 20 años en las cuales nos hemos hecho la pregunta sobre la enseñanza y el aprendizaje del dibujo. La reflexión es parte de la articulación de diversas dimensiones de la experiencia: la del artista, que continúa con su sensibilidad creando emociones; la anterior se encuentra con la experiencia docente en la propuesta sobre la enseñanza del dibujo en la época del arte acontecimiento, de la sociedad del conocimiento; y estas dos se relacionan con el investigador que se pregunta por lo complejo en la pedagogía del arte y en especial del dibujo. Los talleres de dibujo fueron realizados por varios años con estudiantes de artes de diversas instituciones en Medellín (Colombia) como son el Instituto de Bellas Artes - hoy Fundación Universitaria - y el Departamento de Artes Visuales en la Universidad de Antioquia. La experiencia en lo sensible nos permite una revisión general de los presupuestos epistemológicos, artísticos y pedagógicos de este saber, el saber del dibujo y de su enseñanza, y la pregunta por cómo aparecen y se desvanecen bucles de retroalimentación que funcionan como códigos, operaciones, y procedimientos en el sistema de enseñanza-aprendizaje del dibujo.

No es posible en este espacio asumir el compromiso de la reflexión sobre la totalidad del sistema de educación artístico, ya que éste, según las Orientaciones (2010), texto que guía la educación artística en la educación básica y media en Colombia, propone que la enseñanza de las artes se diferencia de tres maneras "la formación para las artes (formación de artistas), la educación por el arte (el arte como vehículo de formación de valores y categorías del ser humano) y la educación en el arte (la experiencia estética como salida a las condiciones culturales-sociales)". Por lo tanto nos ubicamos en el aspecto de formación de artistas, formación para las artes. 


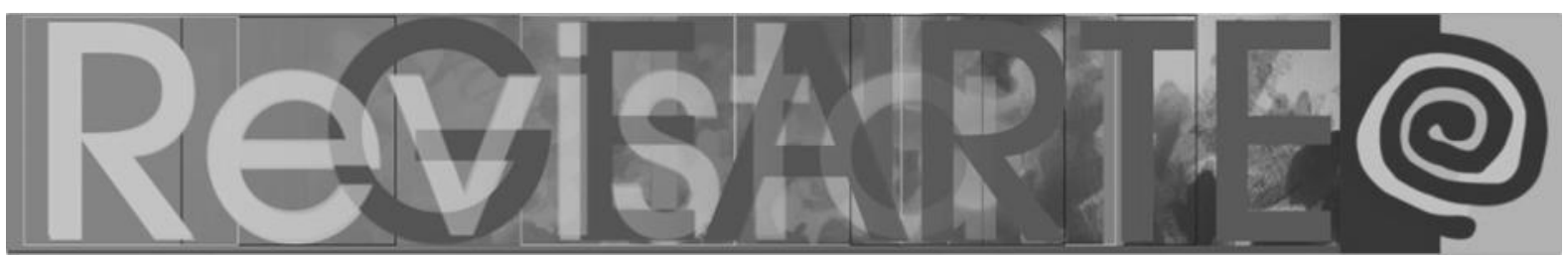

Desarrollaremos primero la aclaración de algunos conceptos para poner en contexto lo que considero las condiciones del siglo XXI, y situar las definiciones y la aproximación teórica que queremos hacer; en esta aproximación se trata de exponer las características de la complejidad desde diversos enfoques para realizar un acercamiento a este paradigma, para luego aproximarnos a una definición desde la teoría que se pregunta por la pedagogía y enseñanza de las artes.

En la segunda parte reconocemos los enfoques del enseñanza-aprendizaje del dibujo, proponiéndolos como obstáculos, para luego encontrar como ellos funcionan en el sistema actual como bucles que perduran y permanecen como atractores en el sistema; estos enfoques conviven evolutivamente con otros códigos, operaciones y procedimientos.

Por último, revisamos una propuesta del enseñanza-aprendizaje del dibujo desde la complejidad; en ésta se destacan diversas rutas que proponen explorar algunas de las operaciones y procedimientos que emergen en el espacio de interpenetración entre el sistema de artes y el sistema pedagógico.

\section{Características de la complejidad}

Desde el siglo XIX se venían presentando diversas alternativas matemáticas y problemas de la física que no estaban resueltos por el método tradicional, es decir por las formas de pensamiento establecidas, por la física mecánica clásica, por la lógica clásica y las geometrías euclidianas. Ya para inicios del siglo XX se presentan los trabajos de Einstein sobre relatividad (1905). Desde otro campo del saber, en la pintura, escultura y el dibujo se conocen rupturas que luego darán paso a las primeras vanguardias del siglo XX, es por esta época, en 1907, que Picasso realiza pinturas de alta ruptura con la tradición como "las señoritas de Aviñón". 


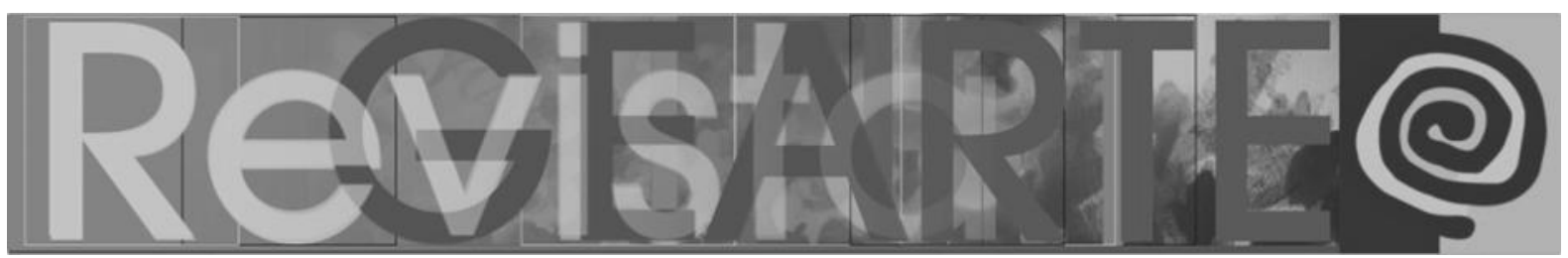

Durante el siglo XX se dan grandes diferenciaciones epistemológicas en la física: como la relatividad, la cuántica y teoría del caos o complejidad (REGULES, 2016). En cuanto a la complejidad, su desarrollo se puede situar a mediados y finales del siglo XX; se presenta desde diversas ciencias, no sin decir que sus inicios tienen referentes en teorías de principios del siglo $X X$ o fines del siglo $X I X$ (MALDONADO, 2015). Mientras que en las artes se manifiestan las vanguardias, las transvanguardias, el posmodernismo y las artes expandidas, en síntesis, llamaremos premodernidad, modernidad, posmodernidad y sociedad del conocimiento a estos momentos del desarrollo cultural.

Una de las rupturas con la física clásica y con el pensamiento estructural es lo que denominamos hoy pensamiento complejo y teorías del caos. En sus inicios no se tiene certeza de los conceptos unificadores, pero ya para la década de 1990 se encuentran seguridades que permiten señalar algunas de las condiciones generales de este paradigma. En los escritos, ensayos y textos de varios autores se informa sobre las condiciones de diferencia entre los paradigmas anteriores y las semejanzas de las ciencias en el nuevo paradigma emergente Gleick (2012).

Estos conceptos sobre el cambio de enfoque en las ciencias naturales y sociales se expresan en Morin (1995), que analiza la necesidad del cambio de paradigma y de pensamiento, partiendo de la sociología. Sus conceptos argumentan su propuesta sobre "la reforma del pensamiento sociológico" (MORIN,1995, p. 15). Este cambio propone combinar el empleo del método científico y otros saberes no estrictamente científicos como la literatura.

Por otra parte, en Wagensberg (1987), en el texto "Ideas sobre la complejidad del mundo", nos dice:

\footnotetext{
Este ensayo parte del conocimiento científico y, en particular, de un concepto que la ciencia moderna intenta aprehender sin haber conseguido todavía definir satisfactoriamente. Es la complejidad. Las preocupaciones fundamentales son dos: el cambio y la relación entre los todos y sus partes. La primera se refiere a la estabilidad y la evolución, la segunda a la estructura y la función". (WAGENSBERG,1987, p. 9).
} 


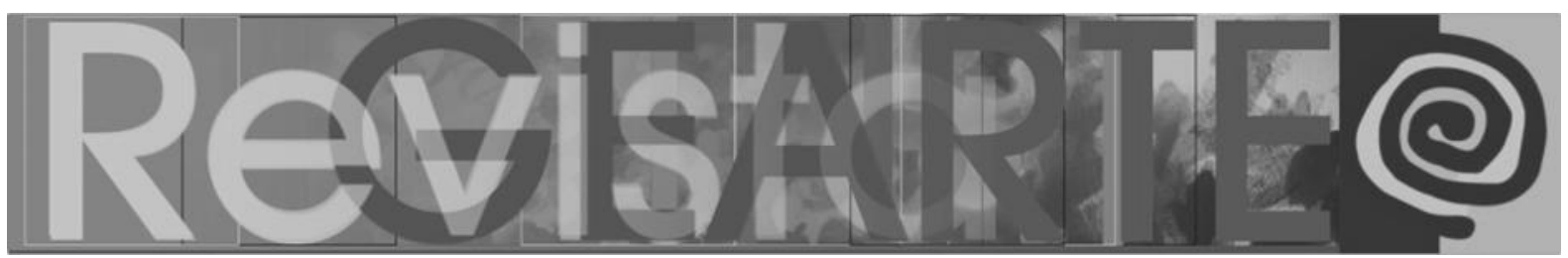

Definidos así los parámetros para acercarse a la complejidad, entendemos que los fenómenos sociales, la pedagogía y la enseñanza de las artes, pueden ser fenómenos complejos en su devenir, en su evolución y en su estructura actual, ya que la realidad del siglo XXI no ofrece las mismas estabilidades que las estructuras sociales anteriores, tanto en el plano de las relaciones humanas como en las condiciones de la sensibilidad.

En el célebre texto "Caos, la creación de una ciencia" James Gleick en 1987 (2012 en español) trabaja crónicas sobre el nacimiento de las ciencias del caos. En él se aclaran los pasos y controversias que tuvieron que enfrentar los pioneros de esta mirada. Tenemos por ejemplo a Edward Lorenz (1964), teoría del caos, Benoît Mandelbrot (1977), geometría de fractales, llya Prigogine (1990-1997), en termodinámica del no equilibrio.

Para Gleick de las tres revoluciones que la física tiene en el siglo XX: relatividad, cuántica y caos, "la del caos importa al mundo que vemos y tocamos, a los objetos de proporción humana. La experiencia cotidiana y las imágenes reales de cuanto nos rodea se han convertido en fin legítimo de la investigación" (GLEICK, 2012, p.15).

Uno de los pilares del pensamiento complejo y las ciencias del caos es el novel Prigogine el cual expresa sus ideas en textos como "Tan solo una ilusión" (1993) y "La Nueva Alianza, Metamorfosis de la ciencia" (1997), este último con Isabelle Stengers. En su visión de la ciencia encontramos conceptos básicos como los de orden, caos y tiempo. Esta postura plantea una nueva mirada que se opone al divorcio que se da entre la ciencia física por una parte y el arte y las humanidades por otra, ruptura que cubre el pensamiento moderno desde el siglo XVIII.

Para estos autores, la modernidad introduce una separación entre las disciplinas, presentando las ciencias naturales con sus leyes y principios lejos de los principios de las ciencias humanas y las artes. La dualidad de culturas se puede cuestionar en el siglo XXI partiendo de la complejidad, como lo dice Prigogine y 


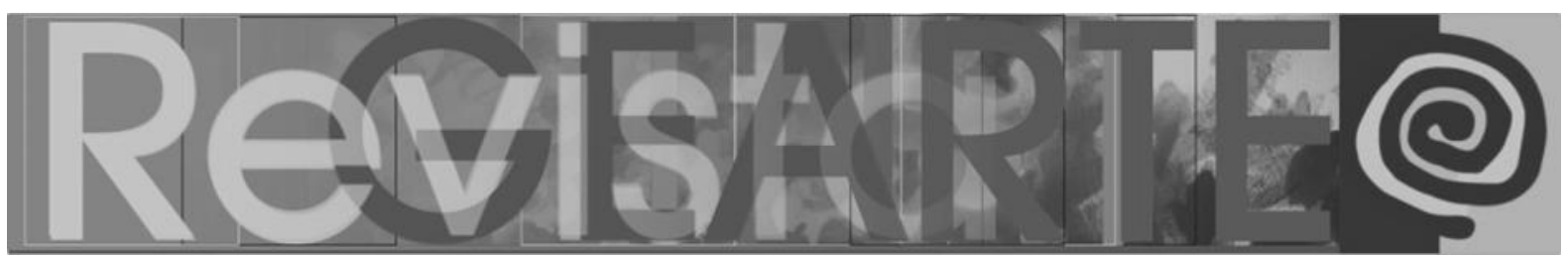

Stenger, "ha llegado el momento de nuevas alianzas, ligadas desde siempre, desde mucho tiempo desconocidas, entre la historia de los hombres, la historia de sus sociedades, de sus conocimientos y la aventura exploradora de la naturaliza" (PRIGOGINE; STENGER, 1997, p. 325).

Con este pensamiento nos vamos acercando a una comprensión de la complejidad como el estudio de los fenómenos "del equilibrio dinámico" de los sistemas con estructuras disipativas que están entre la entropía (el último estado del Universo) y el orden cristalino (que se presenta en las estructuras metálicas frías y cristales con estructuras rígidas). Pero también complejidad como el encuentro de las dos culturas, la humanística y las ciencias exactas en el surgimiento de una alianza de las miradas entre ciencia, filosofía y artes.

En las artes sería el estudio de la ausencia de orden (que no podría ser comparada con el expresionismo abstracto ya que este tiene algún grado de orden temporal) y las expresiones que se mueven entre los límites de las estructuras conformadas por leyes de proporción egipcias (rígidas) pasando por proporciones clásicas griegas y luego por las geometrías euclidianas y proyectivas hasta la deconstrucción de la perspectiva por el cubismo y la entrada de las artes expandidas y los fractales.

En el texto "Complejidad: ciencia, pensamiento y aplicaciones" Maldonado nos dice:

\footnotetext{
El estudio de los fenómenos de Complejidad creciente marca un contraste grande con la ciencia clásica, a partir de seis motivos precisos con los que, de manera habitual, se trabaja de manera integrada y complementaria en complejidad:

- Trabajo con no linealidad.

- Incorporación del principio de incertidumbre.

- Identificación de los puntos críticos o de los estados críticos de un sistema y el estudio de las transiciones de fase y el trabajo con espacio de fase.

- Reconocimiento de la aleatoriedad.

- Bucles positivos y negativos de retroalimentación.

- Importancia del tiempo y de la flecha del tiempo. (MALDONADO, 2007, p. 108).
} 


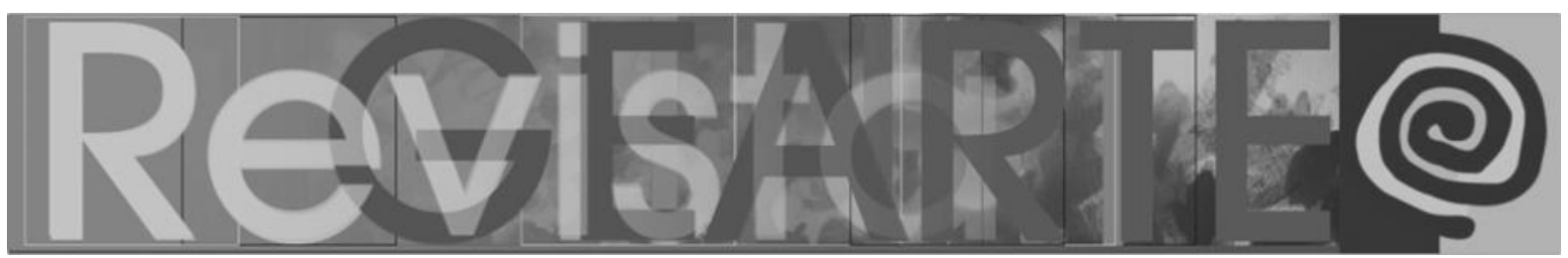

Las ideas de caos-orden y complejidad son retomadas por Colom que nos dice que "la teoría del caos entonces nos deconstruye la teoría al mismo tiempo que nos permite una nueva construcción del conocimiento pedagógico" (COLOM, 2002, p.160). Basados en esas premisas enunciaremos, siguiendo a Colom, algunas de las fortalezas caóticas de la educación, entre otros:

- En la esencia de la educación encontramos la dialéctica orden-desorden explícita en la teoría del caos.

- El caos se da en los procesos que se inscriben en la educación, tenido en cuenta que, entre los componentes se da un entramado de relaciones hipercomplejas.

- Los procesos caóticos se dan tanto en el desarrollo de las personas, como en los procesos educativos.

- La violencia en la escuela podría analizarse desde los planteamientos propios de la teoría del caos.

- El currículo puede ser entendido como atractores reordenados por diversos criterios.

Estos rasgos distintivos nos dan la posibilidad de entender la complejidad en sus diversas dimensiones y nos llaman la atención para producir una serie de preguntas como las siguientes:

¿Cómo apuntan estos postulados a la reorganización de la pedagogía de las artes? y ¿cómo impactan estas ideas en las estrategias de la enseñanza del dibujo en este momento? ¿Cómo expresar caos, fractales, bucles y sinergias en estrategias específicas de enseñanza-aprendizaje del dibujo? Iniciar la reflexión sobre este entorno de la complejidad es el reto que propongo para este momento y que espero pueda sondear y cuestionar.

\section{Enfoques de la enseñanza-aprendizaje del arte en la premodernidad, modernidad y posmodernidad}

Propongo una distinción por enfoques y tendencias que tiene como criterio principal la diferencia entre premodernidad, modernidad, posmodernidad y 


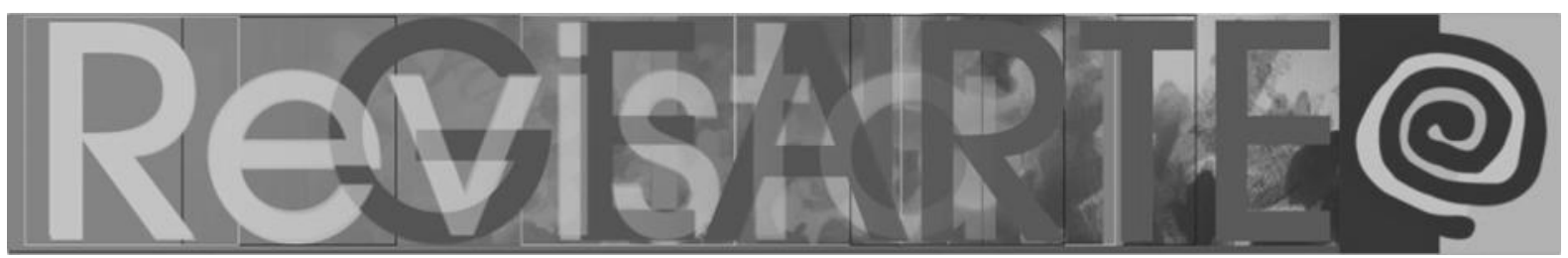

sociedad del conocimiento en la cual está presente el pensar desde la complejidad.

Ya que las propuestas de enseñanza del dibujo no solo están fundamentadas en la técnica sino también en los modos de la sensibilidad de cada época.

Como premoderno podemos distinguir aquello que está dispuesto a develar las realidades trascendentes como el espíritu, las fuerzas invisibles y el más allá, siendo sus relatos el mito y la religión.

El discurso de la modernidad se refiere según Diaz a "leyes universales que constituyen y explican la realidad. Algunos de sus términos son determinismo, racionalidad, universalidad, verdad, progreso, emancipación, unidad, continuidad, ahorro, mañana mejor" (DIAZ, 2009, p. 19).

El discurso de la posmodernidad sostiene, según la misma autora:

[...] que solo puede haber consensos locales o parciales (universalmente acotados), diversos juegos de lenguaje o paradigmas inconmensurables entre sí. Algunos de sus términos son deconstrucción, alternativas, perspectivas, indeterminación, irreversibilidad, descentralización, disolución, diferencia" (DIAZ, 2009, p. 19).

En la actualidad el discurso de la complejidad, enmarcado en la sociedad del conocimiento concentra sus estudios, según Maldonado (2013), en:

\footnotetext{
El movimiento, no control, no estabilidad, no predictibilidad. Esto es, los sistemas en movimiento que pueden ser súbitos, imprevistos, irreversibles.

Los lenguajes del caos, de fractales y de sinergias.

Los dos problemas de la complejidad son el tiempo y la no linealidad. (MALDONADO, 2013, 2:06:54)
}

Las diferencias en la enseñanza-aprendizaje del dibujo están en correlación con estos conceptos, y por lo tanto trataré de ampliarlos para responder a la pregunta, ¿cómo enfocar la enseñanza del dibujo en la contemporaneidad en el marco de lo transdisciplinar que bordea la complejidad?

Imanol Aguirre Arriaga (2005; 2006) nos dice en su texto "Teorías y prácticas en la Educación Artística", de igual forma en "Modelos formativos en educación 


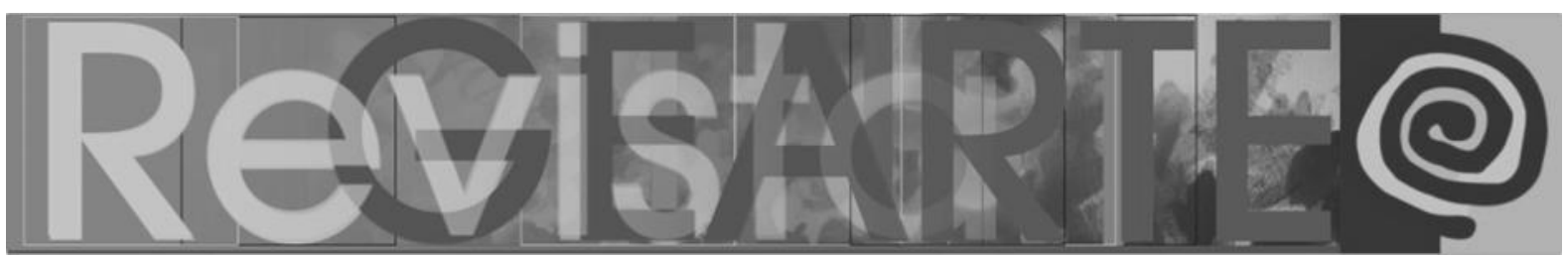

artística", que existen unos parámetros para establecer separaciones entre modos de enseñanza de las artes. Retomando estas diferenciaciones las nombraré tendencias dentro de enfoques de la enseñanza de las artes, ya que propongo los enfoques como categorías amplias no regulatorias, y las tendencias como estrategias que se pueden ubicar en estos enfoques por sus propuestas sobre la enseñanza del arte. Los enfoques los clasifico según las categorías de lo premoderno, lo moderno, lo posmoderno y la contemporánea sociedad del conocimiento. Si me permiten esta organización, podremos acceder a una propuesta.

Hay que anotar que Guasch (2008) nos propone hablar de períodos como el premoderno o precolonial, moderno o colonial y el período poscolonial, posmoderno que tiene su parangón en la ideología multiculturalista. Pero en este artículo no utilizaré esta clasificación ya que es necesario ampliar críticamente la propuesta para Colombia.

\section{Enfoques premodernos}

Estos deben su concepción al uso del símbolo y de sus representaciones. Nos dice Eliade: "evidentemente, la realidad se manifiesta, para la mentalidad arcaica, como fuerza, eficacia, y duración. Por ese hecho, lo real por excelencia es lo sagrado; pues solo lo sagrado es de un modo absoluto, obra eficazmente, crea y hace durar las cosas." (ELIADE, 1984, p. 18). Esto se representa en la enseñanza del dibujo desde las condiciones de la representación, por lo tanto, se dibuja en términos de la concepción reinante, desde lo ontológico. Para entender el concepto "designamos como ontología el resultado de una forma de observar que parte de la distinción ser/ no-ser y que todas las demás distinciones las subordina a esta distinción" (LUHMANN, 2007, p. 710). Así consideramos que, en la premodernidad se representa la realidad como un reflejo del ser que es inmutable, de lo metafísico y lo divino. 


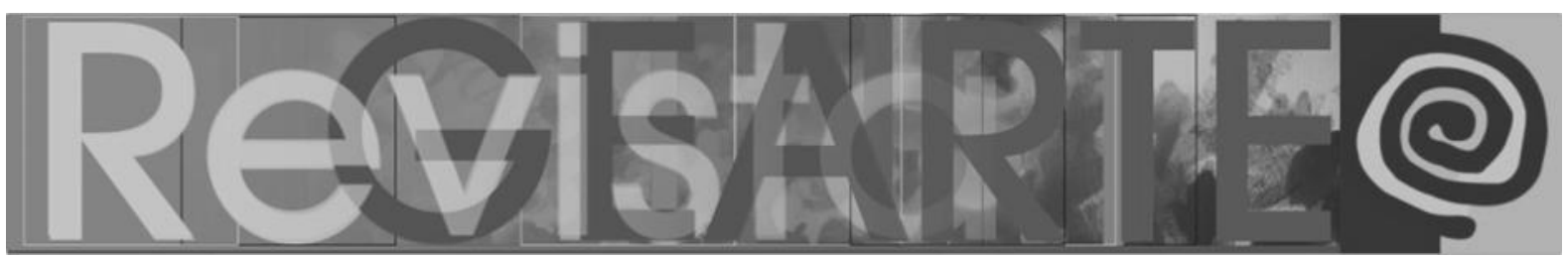

Mediante el acto de creación nos dice Eliade "se cumple el paso de lo no manifestado a lo manifestado o, hablando en términos cosmológicos, del caos al orden" (ELIADE, 1984, p. 24), por lo tanto, según esto, el artista hace que lo invisible se manifieste en lo visible y el arte manifieste el orden de las teorías geométricas que gobiernan o rigen el orden de las cosas. La divina proporción, el número de oro o el sólido platónico.

Efland nos dice que según Aristóteles "el principal objetivo de la enseñanza del dibujo era convertir a los estudiantes en jueces de la belleza de la forma humana" (EFLAND, 2002, p. 32). En la edad media "la enseñanza se realizaba a través de la imitación del maestro o de los asistentes, y el resultado se juzgaba en términos de la exactitud de la imitación" (EFLAND, 2002, p. 32). Pero es en la modernidad que se multiplican las posibilidades, por lo tanto, desarrollamos las diversas tendencias del enfoque moderno.

\section{Enfoques desde la modernidad}

Como ya se ha expresado la modernidad puede corresponder a términos como determinismo, racionalidad, universalidad, verdad, progreso, emancipación, unidad, continuidad y en la enseñanza del arte y el dibujo se expresan en diversas tendencias como: logocentrismo, expresionismo, filolinguismo.

La modernidad concuerda con las ideas conductoras de la unidad, y la emancipación; nos dice Welsch "en la Ilustración dicha emancipación se lograba por la ciencia; en el Idealismo, por la teleología del espíritu; en el marxismo, por la liberación de la humanidad a través de la revolución del proletariado; en el capitalismo, por la felicidad de todos gracias a la riqueza; en la era tecnológica, por la resolución definitiva de los problemas mediante la maximización de la información" (WELSCH, 1997, 37). Esto se refleja en las siguientes tendencias de la educación artística: 


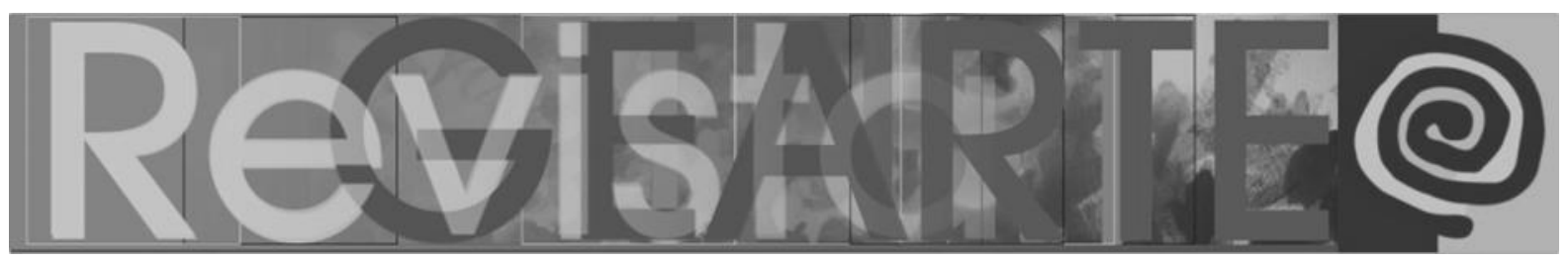

\section{La tendencia Logocéntrica}

En la tendencia Logocentrista podemos resaltar la Fundación Getty, la cual defiende la educación artística como disciplina bajo las denominaciones de DBAE (educación artística basada en disciplinas) o DBME1․ Los propósitos formativos pueden ser "que el educando adquiera y domine los preceptos que rigen la virtud estética en las artes", (AGUIRRE, 2006, p. 2). "Dichos conocimientos le permiten aspirar a alcanzar el ideal de belleza en sus obras". (AGUIRRE, 2006, p. 2). Entiendo que sería un ideal basado en el orden y el equilibrio, en las proporciones griegas o clásicas de la figura humana y el orden universal, pero no desde lo sagrado sino desde el concepto de orden mecánico, matemático. Dice Aguirre: "casi todos los métodos prevén una secuenciación en la enseñanza a partir de modelos que pasa por el dibujo de orlas o elementos decorativos, partes de la anatomía humana y el cuerpo humano en diferentes posiciones, es decir de lo fácil a lo difícil o de las partes hacia el todo" (AGUIRRE, 2005, p. 214).

En el dibujo actual, la tendencia Logocentrista busca el ideal clásico, propio del contexto cultural de la Europa del siglo XVII y XVIII. La buena obra de arte está sujeta a reglas y principios universales. El hecho artístico, según este modelo educativo, no procede de la acción individual, sino del conocimiento y puesta en uso de los principios de la proporción y la armonía, principios universalizables, reconocibles por el experto y directamente derivados del uso de la razón. (AGUIRRE, 2006, p. 2).

Como estrategia metodológica se tiene, el respeto por la norma y el procedimiento, la dirección sabia y experta y el empleo de una práctica didáctica sistematizada y precisa. Se adquiere la posibilidad de una imitación del objeto y la progresión en la calidad del dibujo. Podríamos decir un método racionalista que

1 Discipline-Based Music Education (nota das editoras). 


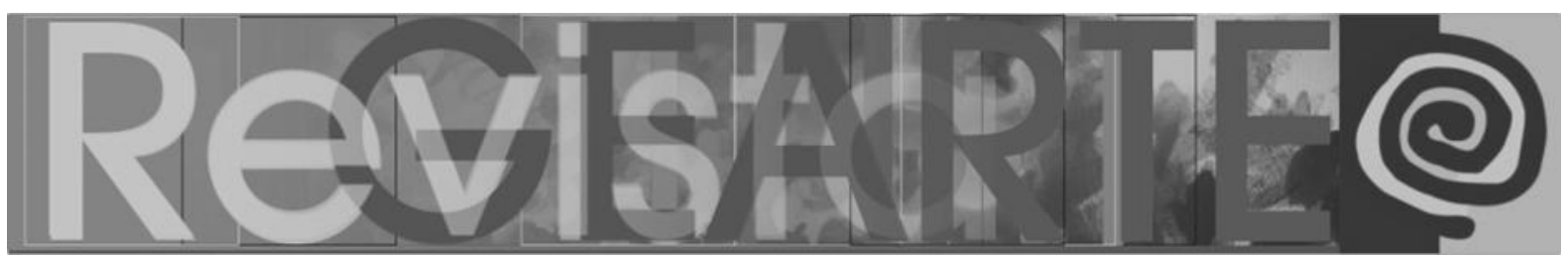

practica la proporción, la medida aurea, la perspectiva y sobre todo el encuadre y el encaje.

Entre las limitaciones de esta tendencia está la condición del predominio de los procesos racionales y por lo tanto el dibujo es producto de una técnica, con la rigidez y la solemnidad de un cuadro clásico.

\section{La tendencia Expresionista}

La segunda de las tendencias será la Expresionista, que considera el niño como ideal antropológico, encontramos que sus propósitos formativos parten de los planteamientos idealistas que Schiller desarrolla; éste los expone en sus "Cartas para la Educación Estética del Hombre". Sir Herbert Read, nos comenta Aguirre (2005, p. 226), concreta esta tendencia en su "Educación por el arte", estableciendo que el propósito principal de la educación artística debe consistir en usar las artes, en tanto que actividad más elevada del ser humano, para conducir a éste al estadio final y definitivo de su proyecto antropológico, al encuentro con sus esencias y a su redención final. Entre los autores esta Benedetto Croce, Lowenfeld y Brittain, Stern, Freinet. Se espera que en el dibujo el sujeto exprese sus sentimientos y no necesariamente se apegue a los cánones clásicos o sociales de la belleza, sino que deje intuitivamente sus rasgos individuales más fundamentales.

Nos dice Efland que "entre las décadas de 1920 y 1940 varios artistasprofesores se dedicaron a desarrollar un método de autoexpresión creativa" (EFLAND, 2002, p. 294). Ellos consideraban que el docente además de artista debía tener una gran sensibilidad y a la vez el niño es considerado como artista con una gran voluntad de expresión.

Esta tendencia se refiere a la actuación espontánea del sujeto que no atiende a normas previamente establecidas, se parte del erróneo principio, nos 


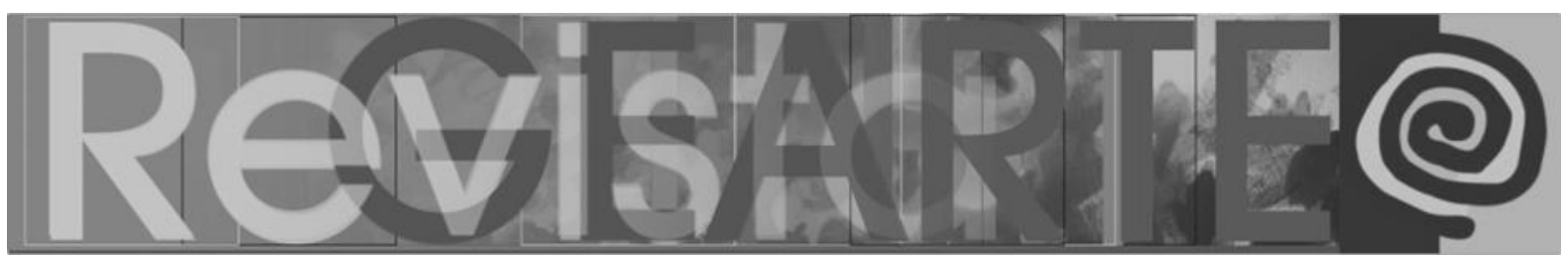

dice Aguirre, de que las cuestiones referentes a la creación artística son de índole subjetivo.

En este momento un curso de dibujo basado en el expresionismo está fundamentando en seguir como modelo a los grandes mitos del romanticismo, entre ellos, Van Gogh. Pero también introducen la concepción de la infancia y en la cultura se refleja esa observación de los niños desde su propia identidad. Con estas dos posiciones se puede concebir, en el expresionismo, el arte como la manifestación más legítima del ser interior.

En el expresionismo la infancia se introduce como un estado próximo a la naturaleza de lo humano, y en Schlegel, se entiende la complementación de la creación, el pensamiento y el arte moderno, y de libertad que se presenta en los niños, los locos y los primitivos, y por lo tanto en este estado el hombre refleja su interior en sus obras, por lo cuales estas adquieren un repentino interés. Las obras reflejan ese estado de discordancia, ese "malestar en la cultura" (FREUD, 1979) que se percibe como contraposición a los valores y normas de la cultura occidental.

El encuentro de la visión innatista del artista, con la del niño como ideal antropológico y la de la creatividad, como expresión del ser interior, configuran el triángulo sobre el que se sustenta un modelo formativo que renuncia al aprendizaje y la relación con la cultura en beneficio de la libre expresión de la natural espontaneidad y creatividad del sujeto (AGUIRRE, 2006, p. 5).

El expresionismo, en la actualidad, como estrategia metodológica, propone la ausencia de programas definidos y presta una escasa atención a la formación de los profesores encargados de esta tarea. La metodología está fundamentada en la libertad creativa frente a la instrucción (AGUIRRE, 2006, p. 6).

\section{La tendencia Filolingüísta}

La tendencia Filolingüísta se centra en la alfabetización visual como fundamento disciplinar de la educación en el arte. Los autores se basan en D. A. 


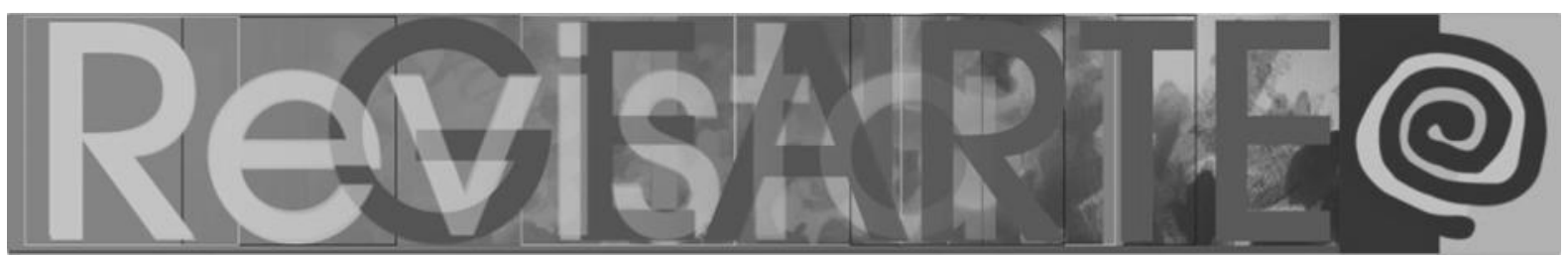

Dondis (1976), en la lectura de la imagen y en las propuestas estructurales de la imagen. Los propósitos formativos pasan por la propuesta de alfabetizar visualmente a los estudiantes para que sean capaces tanto de decodificar los recursos expresivos ocultos en cada imagen, como usarlos para la propia creación artística. De modo que la formación perseguiría la competencia en la "emisión" y, sobre todo, en la "lectura" de los mensajes visuales. (AGUIRRE, 2006, p. 8).

Debe el estudiante desarrollar las habilidades del ver-observar, las habilidades de lectura para decodificar las imágenes o mensajes visuales. Producir imágenes o mensajes visuales. $Y$ se debe posibilitar las habilidades para emitir mensajes con y sobre las imágenes.

La tendencia filolingüísta considera el arte en el sentido de los signos, como un lenguaje programado establecido desde la semiótica para otras expresiones culturales (AGUIRRE, 2006, p. 7). El punto, la línea, la superficie, el color, la luz o la textura; estos elementos se coordinan entre sí, dando lugar a una especie de estructuración de una gramática de las formas, que haga posible la determinación de códigos visuales, el mismo Dondis lo dice:

\begin{abstract}
Existe una sintaxis visual. Existen líneas generales para la construcción de composiciones. Existen elementos básicos que pueden aprender y comprender todos los estudiantes de los medios audiovisuales, sean artistas o no, y que son susceptibles, junto con técnicas manipuladoras, de utilizarse para crear claros mensajes visuales. El conocimiento de todos estos factores puede llevar a una comprensión más clara de los mensajes visuales. (DONDIS, 1976, p. 15).
\end{abstract}

Por ello, las estrategias metodológicas que emplean los partidarios de este método formativo tienen su centro de acción en el análisis. El modelo filolingüístico promueve la experimentación y combinación consciente de los elementos constitutivos de lo plástico. Para ello, "no renuncia a la dirección del experto ni a la sistematización curricular” (AGUIRRE, 2006, p. 9).

Lo acompañan los textos sobre psicología de lo visual como la Gestalt en Arte y Percepción Visual, de Arnheim (1970) el cual desarrolla el análisis de temas 


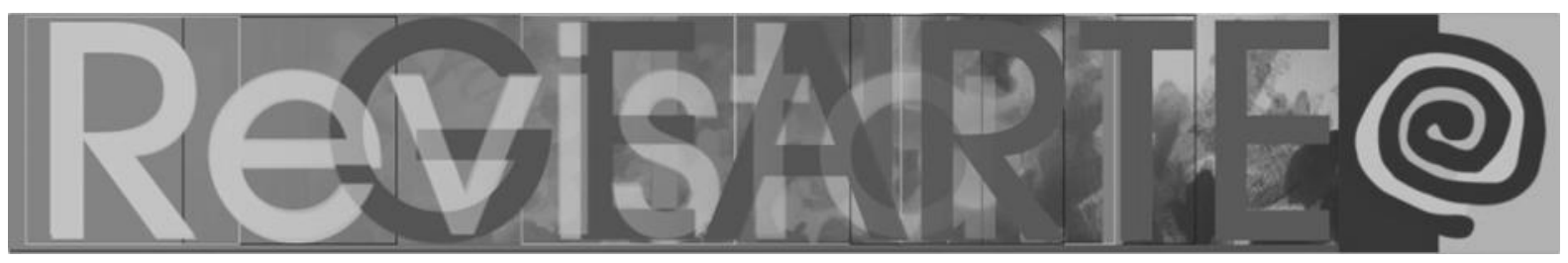

como el equilibrio, la forma, la significación, el desarrollo, el espacio, la luz, el movimiento, la tensión y la expresión.

Estas propuestas filolinguistas y de la Gestalt permitieron formalizar en la educación una propuesta estructural, un lenguaje sobre la enseñanza del dibujo y trabajar sobre una estrategia moderna de los lenguajes del arte, que luego fue puesta en cuestión por su excesivo formalismo y sistematización de la gramática del arte.

En la actualidad un curso de dibujo basado en la filolinguistica de la que se desprende la semiótica, se propone reconocer los aspectos del lenguaje, la composición, el ritmo, el espacio, la luz el fondo y la figura, acercándose a la interpretación y la creación desde los valores formales. El docente propondría ejercicios formales que consideraría propios para el desarrollo de una obra de arte desde el signo visual. Este ejercicio no se puede confundir con el trabajo de Kandinsky “De lo espiritual en el arte”, mucho más musical y estético que semiótico.

\section{Los enfoques posmodernos}

Un currículo posmoderno presenta características y regularidades en diversas tendencias, estas características según Efland, Freedmann y Stuhr (2003, p. 157) son el predominio de los pequeños relatos (Lyotard) como respuesta al rechazo de los metarrelatos. Otra característica es la respuesta a la relación saberpoder (Foucault) por lo que se horizontaliza las relaciones entre arte elevado y arte popular. Una tercera característica se observa en la apropiación del método de crítica cultural (Derrida) que se denomina deconstrucción. Por último, la apropiación de la doble codificación (Jencks) por la cual se estima que los objetos comunican mensaje a los espectadores a través de distintos códigos.

Estas se objetivaban en diversas tendencias como la educación referida a la cultura visual. 


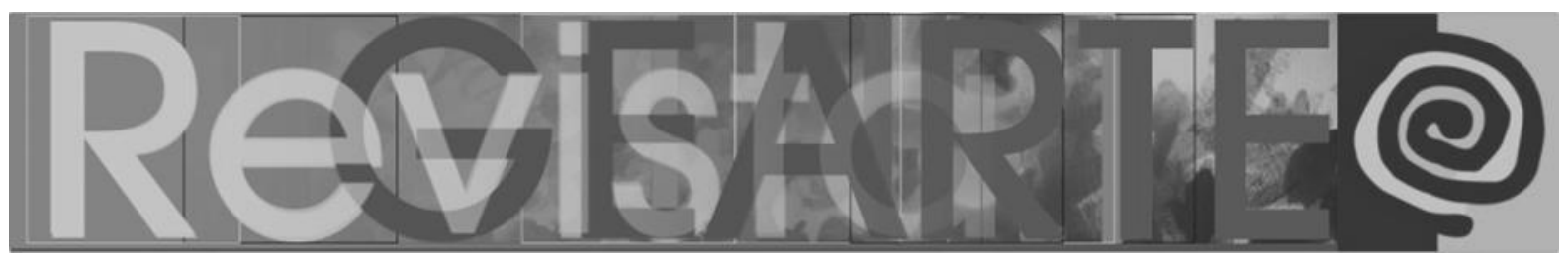

\title{
Tendencia de la cultura visual
}

La Educación Referida a la Cultura Visual es uno de los enfoques de la visión posmoderna, impulsada en España por el profesor Fernando Hernández, de la Universidad de Barcelona.

En cuanto a los propósitos formativos, de la educación artística basada en la cultura visual, se puede reconocer el de proporcionar a los estudiantes herramientas para una comprensión crítica del papel que cumplen en cada sociedad los instrumentos visuales de mediación cultural y la posición que ocupan en el juego de las relaciones de poder. Según Aguirre (2006):

\begin{abstract}
Hernández precisa, no obstante, que hablar de comprensión crítica no significa sólo referirse a la valoración individual, sino a la aplicación consciente y sistemática de diferentes modelos de análisis (semiótico, estructuralista, deconstruccionista, intertextual, hermenéutico, discursivo...) en el estudio de la cultura visual" (AGUIRRE, 2006, p. 12).
\end{abstract}

Como estrategias metodológicas afrontan las representaciones de la cultura visual, incluidas las artes, como narrativas que reflejan prácticas sociales y culturales. Emplea tácticas de aplicación de los fundamentos de la oposición, la inversión, la intertextualidad, la deconstrucción o el análisis del discurso que, si bien no pueden considerarse herramientas estrictamente metodológicas en todos los casos, ofrecen resultados interesantes si son adaptadas a las prácticas didácticas. Promueve además una actitud investigadora que presta atención a todas las circunstancias que rodean la producción del hecho artístico y al de las formas en las que culturalmente es recibido. Hace énfasis en "sustituir la idea de una estética universal, por la de las estéticas locales" (AGUIRRE, 2005, p. 312).

En la actualidad un curso de dibujo basado en la cultura visual propondría un análisis del dibujo de imágenes que les rodean y que pueden atender cualidades como: ser inquietantes, reflejar las voces de la comunidad, referirse a la vida de la gente, no ser herméticas entre otras (AGUIRRE, 2005, p. 311). 


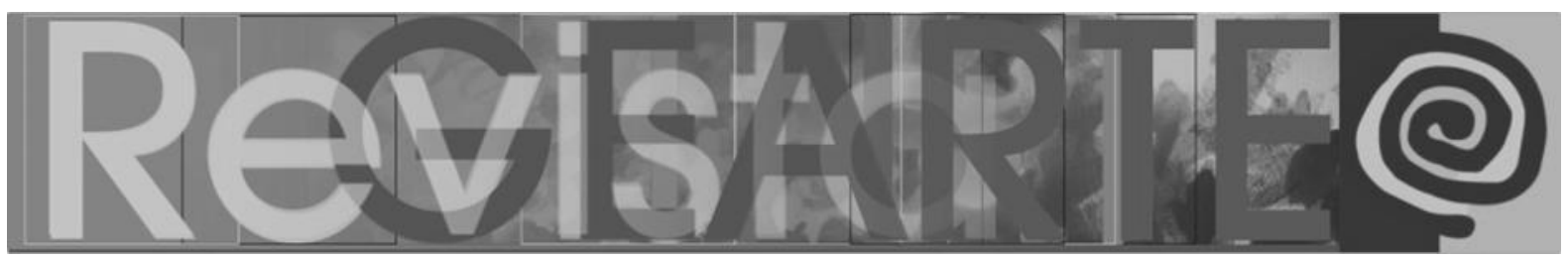

\title{
La aproximación pragmatista
}

Por último, según Aguirre se puede estudiar la Aproximación Pragmatista, que tiene como centro el mismo Imanol Aguirre Arriaga. Esta tendencia presenta una análoga visión pragmatista como Richard Rorty. Los propósitos formativos tienden a establecer una relación orientada hacia el enriquecimiento personal o, como dice Rorty, a la "creación de sí mismo". Dice Aguirre:

\begin{abstract}
La educación artística es idónea, en este sentido, para desarrollar una identidad liviana, contingente, porosa y abierta a aceptar al otro y es eficaz para la transformación y la reconstrucción social en tanto que este tipo de identificación con el otro nos predispone a ser sensibles ante su humillación. (AGUIRRE, 2006, p. 16).
\end{abstract}

Las experiencias en lo estético no arreglan nada por sí mismas, como no lo hace el arte, pero contribuyen a proporcionar una diversificación y ampliación de las creencias personales y un enriquecimiento de la sensibilidad (AGUIRRE, 2006, p. 16).

Como estrategias metodológicas el autor propone entre otras, la restauración del equilibrio entre comprensión y producción en educación artística. Dice Aguirre: "Propongo la producción comprensiva como un método interpretativo y formativo que encuentra en la producción artística una herramienta para la interpretación de la cultura" (AGUIRRE, 2006, p. 16), y continúa diciendo que, según la perspectiva pragmatista, el objetivo final de la comprensión estética sería el enriquecimiento de la experiencia, ante la que el análisis debería pasar a segundo plano, y por lo tanto el análisis debe servir para situar la obra en un entorno cultural; en ningún caso para sustituir o reproducir la plena experiencia de la obra de arte.

Frente a estas estrategias y tendencias podemos asumir primero una mirada comparativa entre ellas, pero también una propuesta que las enfrente a las realidades del siglo XXI en cuanto a los cambios de las realidades sociales, 


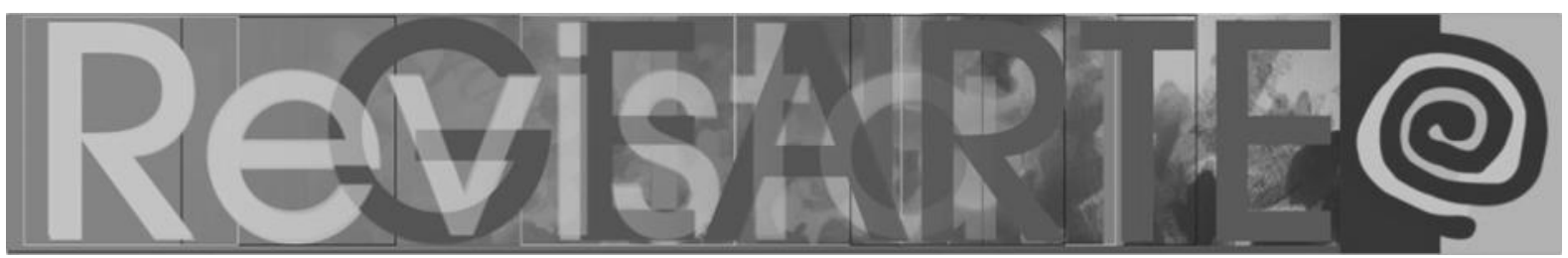

epistemológicas, económicas, políticas y culturales y sobre todo de la sensibilidad, que tratamos de observar y comprender desde teorías como la complejidad.

\section{Bucles de realimentación positivos y negativos}

Hasta aquí se ha presentado una organización clásica de las ofertas de enseñanza de las artes visuales y del dibujo, pero si proponemos entender este panorama como no lineal, con principios de incertidumbre, con el reconocimiento de la aleatoriedad, describiendo bucles positivos y negativos de retroalimentación y entendiendo la importancia de la flecha del tiempo, no es posible hacer un recuento sino una re-disposición o re-localización del problema y trabajar sobre bucles de realimentación que se presentan en la actualidad y mostrar cómo se establecen códigos y operaciones posibles, que actúan como oferta en la diversidad de la sociedad actual, pero dichas ofertas pueden servir de obstáculo epistemológico, ya que son anacrónicas, sirvieron en el pasado, pero hoy si no se re-localizan, dificultan la apreciación de los cambios en la realidad. Por lo tanto, esta es la reorganización que propongo en el panorama de la pedagogía de las artes.

\section{El código metafísico}

El primer obstáculo tratado será el código metafísico en el enfoque premoderno, que establece apriorismos como el que presupone la existencia de constantes armónicas inmutables, que nos llevan a la belleza mítico-divina; condiciones de la proporción o de la armonía preestablecidas por entes no humanos, que provienen de una fuente metafísica a la que hay que acceder para establecer un modelo mítico del dibujo, un modelo divino, una verdad eterna. Esta tendencia puede comprenderse como un acceder a lo preestablecido en el canon, solo lo metafísico es arte, el espíritu canoniza el objeto realizado por el artista del que emana la fe, o la luz por ser parte de lo Divino. 


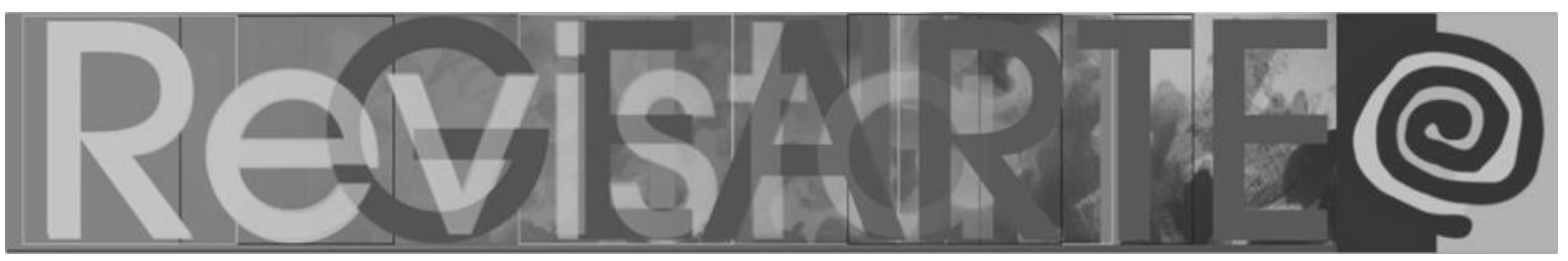

\section{El código sustancialista}

El segundo obstáculo parte del sustancialismo en el enfoque moderno, que dedica el trabajo al valor de la obra, es la obra de arte en sí, la que tiene el poder de ser obra, su estatus está en los materiales y sus compromisos con el tema, el delicado tratamiento de las sustancias y el resultado de la perfección en la obra en sí. La obra de Miguel Ángel es el ejemplo.

Los dibujos en sanguina de Miguel Ángel son la obra por sí misma, ella es la sustancia que ha servido a un artista para lograr en su totalidad la belleza requerida en el arte.

\section{El código antropocéntrico}

El siguiente obstáculo es el antropocéntrico, relacionado con el logocentrismo que encuentra las constantes procedentes de la medida proporcional del cuerpo y de los objetos de la naturaleza estudiadas por la razón; una medida que da la proporción perfecta, la perfección de la naturaleza y del hombre en estas constantes, se conoce como la medida clásica, la renacentista y la del pensamiento neo clásico, los dibujos de Jacques-Louis David son el ejemplo como el dibujo Juramento de los Horacios.

Otro obstáculo antropocéntrico es el basado en la actitud expresionista la cual resalta la primacía del sujeto, en sus necesidades emocionales y su deconstrucción de la racionalidad para dar paso a sus mundos internos o inconscientes. En los dibujos, como los de Vincent van Gogh, se ha considerado el sentido de lo existencial y la primacía del sujeto, no del objeto. Se puede entender que aún permanece la dualidad sujeto-objeto; que nacida en la modernidad pervive en la condición de la epistemología dualista del siglo XIX. En el dibujo expresionista se contribuye a un hombre que en plena libertad se expresa o a un niño en plena naturalidad; esta funciona como obstáculo al centrase solo en el sentimiento y la individualidad del sujeto. 


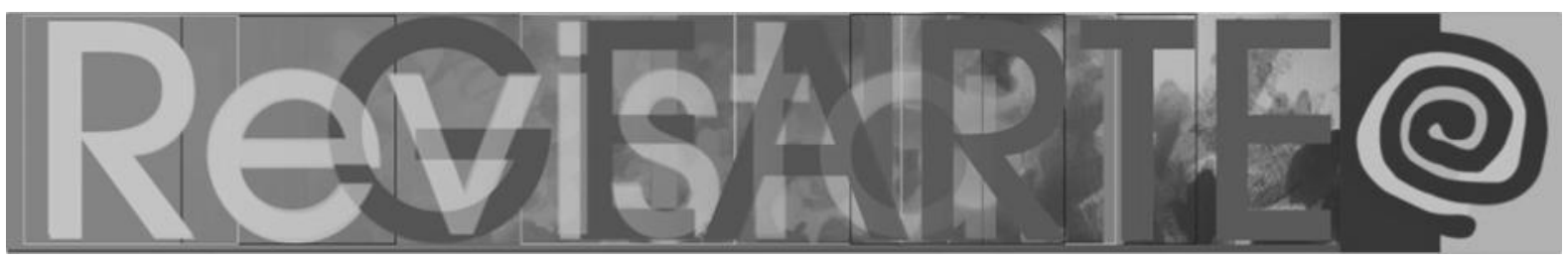

De nuevo una condición antropocéntrica es la aproximación pragmatista no se puede confundir con el dibujo de acción, es como decíamos antes, según Aguirre: "Desde una perspectiva pragmatista, el objetivo final de la comprensión estética sería el enriquecimiento de la experiencia”, enriquecimiento que no tiene como objeto la obra o el dibujo en sí mismo.

\section{El código estructuralista}

Las transformaciones en el siglo $\mathrm{XX}$ generadas desde la física relativista y cuántica, acompañan los cambios de las primeras vanguardias. En estos inicios de siglo se propone una epistemología estructural y llevan a las teorías humanistas a acoger la lectura de los signos como principio y a aplicar la semiótica al estudio de las artes como lenguaje; de ahí se desprenden las teorías del dibujo enseñado como gramática y como sintaxis de la imagen.

El pensamiento de los estructuralistas aplica la estrategia de concebir el mundo en sus dualidades, en opuestos, así lo dice D. A Dondis en su texto (1976): contraste/armonia; exageración/ reticencia; espontaneidad/ predictibilidad; acento/ neutralidad; asimetría/ simetría; inestabilidad/ equilibrio; audacia/ sutileza; transparencia/ opacidad. Estos dualismos funcionan como obstáculo.

Esta estrategia estructural en la que se abarca el lenguaje, da pie para una racionalización de la imagen y una condición de textos que parecen ser manuales con el abc y su gramática. Parece que dibujar se desprende del observar y se establece en la pura condición del signo, para su lógica y su expresión. El problema estructural cae en la condición abstracta en la cual el mundo desaparece como problema. Este espacio es el puro uso del lenguaje, sin recurrir a los modelos externos, las pautas o los referentes. La estructura de la obra se sostiene por sí misma en el formalismo de sus trazos. 


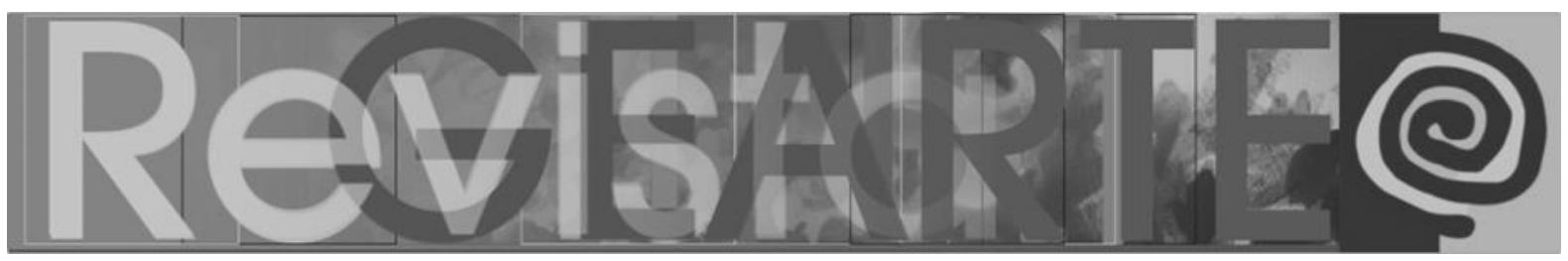

Esta tendencia se aproxima a la Cultura Visual, y encontrará su límite en el análisis, en la no necesidad de la expresión o la formalización de la obra, por lo que no tiende a producir dibujos ya que esta actividad no es su centro de atención.

Frente a estos obstáculos que se encuentran en la enseñanza del dibujo y en la educación artística se propone una ruptura que nos permita entender las diversas facetes que presenta el dibujo y las condiciones de múltiples pliegues unidos en la condición de su producción, la unidad de lo múltiple en la acción de dibujar y el encuentro de los mundos del arte y de la ciencia en la complejidad.

\section{Una propuesta de la enseñanza del dibujo desde la complejidad}

Podemos resumir diciendo que en la primera exposición se presentan las diversas maneras de enseñanza del dibujo como una continuidad histórica, como una superación de etapas, estructuralmente desenvolviéndose. En un segundo momento las tendencias se presentaron como obstáculos, es decir, como condiciones que podrían ser superadas para continuar en un progreso también estructural.

Pero la pregunta es ¿cómo enfocar la enseñanza del dibujo en la contemporaneidad en el marco de lo transdisciplinar que bordea la complejidad?

Para dar respuesta se propone un tercer despliegue, el cual se fundamenta en la teoría de sistemas complejos que muestran cómo pueden convivir evolutivamente diversas manifestaciones en términos de códigos, operaciones y acciones. Por lo tanto, se puede decir que el pasado pervive en muchas manifestaciones actuales, no es superación, es un estado del sistema en el cual pueden ocurrir fluctuaciones, derivas y permanencias de anteriores códigos. Estas permanecías latentes o manifiestas se encuentran en diversas experiencias en las academias de enseñanza del dibujo.

En un seminario taller (ORTIZ; CARDONA, 2013) compartido con el artista John Mario Ortiz, se llevó a cabo una propuesta, de la cual se presenta esta 


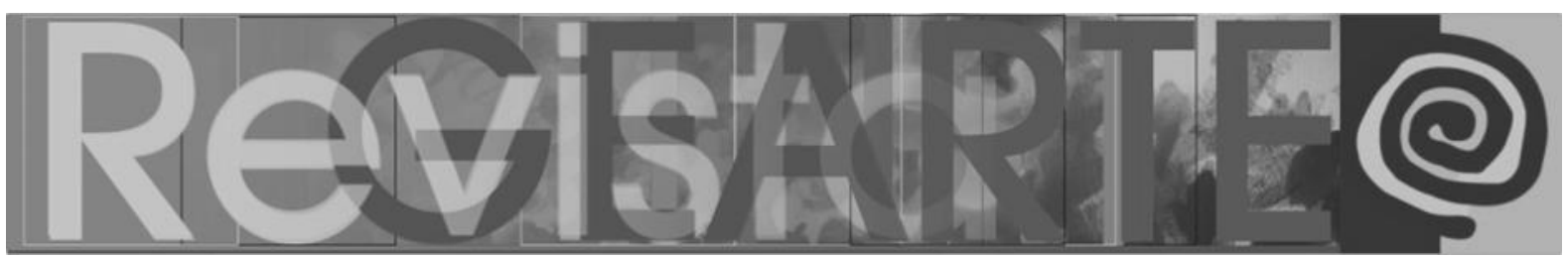

sistematización-teorización como un ejemplo de los posibles caminos para la enseñanza del dibujo. Esta propuesta se realizó bajo la estrategia del dibujo en el campo expandido del arte contemporáneo. Al preparar el semanario taller se escogieron algunas rutas, apoyados en diversas estrategias didácticas.

En la reflexión posterior que presento, basados en las teorías de Luhmann (2007) Mascareño (2009), se parte de entender el arte y su encuentro con la pedagogía como un sistema de comunicación simbólico altamente generalizado, Así el espacio funcional que aparece cuando se encuentra el arte y la pedagogía puede describirse como un sistema complejo en el que se realizan operaciones que emergen en diversos órdenes y se hacen realidad en el acontecimiento. Se propone, en el sistema, la diferenciación de diversos ordenes: el orden de las narraciones, el orden de las acciones, el orden de las relaciones, el orden de los códigos, el orden de los procedimientos entre otros. Así, al reflexionar sobre el seminario taller se puede concluir que se establecieron las siguientes articulaciones entre órdenes y rutas para el dibujo:

- En el orden de las narraciones se sugirieron las dualidades de texto e imagen. El dibujo como escritura y la escritura como dibujo. Apropiaciones del espacio literario desde el dibujo. La poesía visual. La caligrafía y el gesto. También el dibujo como registro de viaje. Con Trayectos y recorridos en el espacio-tiempo, incursiones en el espacio urbano y en los tiempos de lo cotidiano, desplazamientos geográficos, rituales cotidianos. Trabajo de campo. Diarios, bitácoras, cartas de navegación.

- En el orden de las acciones se propuso el Dibujo de acción o dibujo performático. En el cual se hacía explicito el dibujo como registro, huella de una acción corporal. Dibujo y movimiento. Inscripciones del cuerpo sobre una superficie-soporte. El cuerpo como lápiz de dibujo. El gesto y la actitud como formas posibles de dibujo.

- En el orden de los códigos: El dibujo tradicional relocalizado como discurso contemporáneo. Actualizaciones de los procedimientos, herramientas y soportes tradicionales del dibujo; resignificación de los códigos tradicionales de la línea y los valores tonales, representación, proyectación y perspectiva. El dibujo en tres dimensiones. Desplazamiento del sentido del dibujo de las dos a las tres dimensiones. Relación dibujo-escultura, dibujo - intervención, dibujo - 


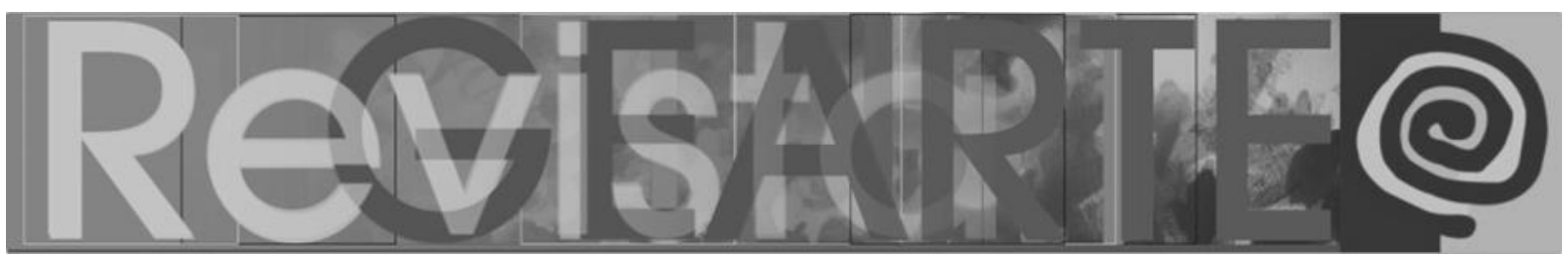

arquitectura, dibujo instalación. Dibujo-objeto. Desde la imagen bidimensional tradicional resemantizaciones de recursos y procesos tradicionales del dibujo.

- Desde el orden de los procedimientos: La exploración de nuevos medios, materiales y soportes de inscripción gráfica. Medios y soportes altenativos del dibujo. Nuevos soportes del lenguaje gráfico. Cruces del Dibujo con otros medios y lenguajes. Soportes, medios y vehículos posibles e inéditos de la expresión gráfica.

En esta ruta se exploraron los nuevos espacios para el punto, la línea, el plano y el tono (luz y sombra.) Procesos de hibridación de recursos, métodos y estrategias provenientes de otros campos de la expresión plástica como la pintura, la escultura, la fotografía, el video, la instalación, el performance, entre otros hibridados con el dibujo.

Además, se propusieron dispositivos de dibujo mecánicos, reapropiaciones de operaciones antiguas con máquinas. Apropiaciones de las nuevas tecnologías y algoritmos en el dibujo, se incluía el dibujo digital y las posibles animaciones.

Como resumen general se puede decir que el contenido del taller permite entender la diversidad en las creaciones de los estudiantes y el encuentro con la no linealidad; la introducción del principio de incertidumbre, acompañado del concepto de contingencia; como también el despliegue transdisciplinar al encontrar relaciones con el cuerpo y la danza, con la video instalación, la arquitectura y los espacios expandidos, desde el dibujo.

Identificamos puntos críticos o de los estados críticos en el desarrollo de la búsqueda de una sensación expresada con el dibujo y el reconocimiento de la aleatoriedad, pues pequeños motivos podían devenir en diversos caminos para la entrega de la obra por parte de los estudiantes.

Entre los pilares de una renovación en la enseñanza-aprendizaje del dibujo se plantearon desde el inicio cuatro impulsos dinámicos para la acción, diversos pero complementarios, para tener en cuenta durante el seminario-taller: la creatividad, el manejo de materiales y soportes, el dibujo como operación en el 


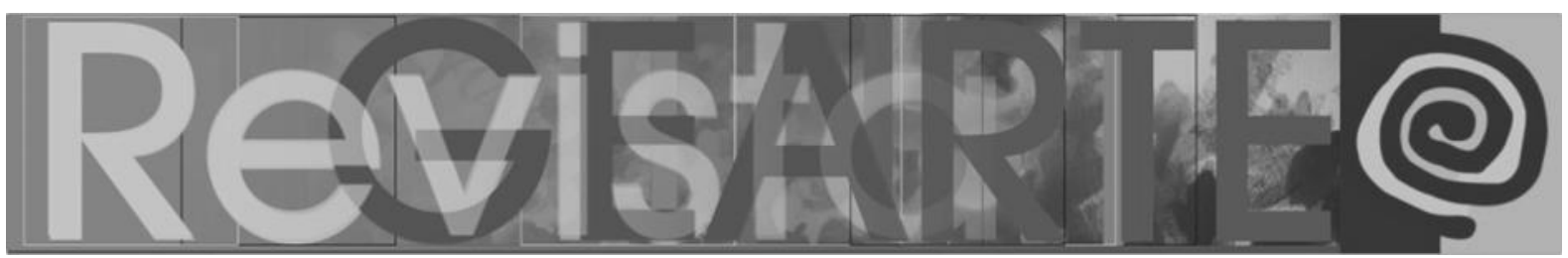

espacio y las estrategias de trabajo en la contemporaneidad. Estos cuatro pilares han dado como resultado una generación de artistas que comprenden el recurso del dibujo como alternativa dinámica y viva en el panorama de las artes y la sensibilidad contemporánea.

\section{Conclusiones}

En la esta oportunidad se debe reconocer el valor del pensamiento complejo ya que permea todas las esferas del desarrollo del saber y por lo tanto también del saber artístico y pedagógico. El pensar desde la complejidad nos acerca a los fenómenos de auto-organización, de fractalidad, bucles de realimentación y autopoiesis que dirigen la mirada sobre la naturaleza y sus representaciones actuales a través del arte.

Los docentes que enfrentan el reto de la enseñanza del dibujo pueden encontrar que los enfoques y tendencias históricamente reconocidos pueden hoy ser pensados de tres maneras: como continuidad histórica que refleja una superación de etapas desenvolviéndose estructuralmente; también los enfoques pueden ser entendidos a modo de obstáculos, es decir, como condiciones que podrían ser superadas para continuar en un progreso también estructural; o por último, según la tesis de este artículo, fundamentados en el pensamiento complejo, considerar desde una mirada evolutiva que el pasado pervive en muchas manifestaciones actuales, se experimenta, en el dibujo y en su enseñanza, una permanecía latente o manifiesta de las experiencias anteriores que se instalan en diversas academias de enseñanza del dibujo y conviven con nuevas alternativas emergentes.

En la actualidad surgen derivas y fluctuaciones que se manifiestan como estrategias de enseñanza y acercamiento dibujístico a la realidad, que recurriendo a las propiedades de los medios de comunicación simbólicos, recurren a desplegar los códigos, operaciones y procedimientos, y así permiten desarrollar alternativas de creación en el dibujo, encontrando que, no es desde la unidad excluyente, sino 


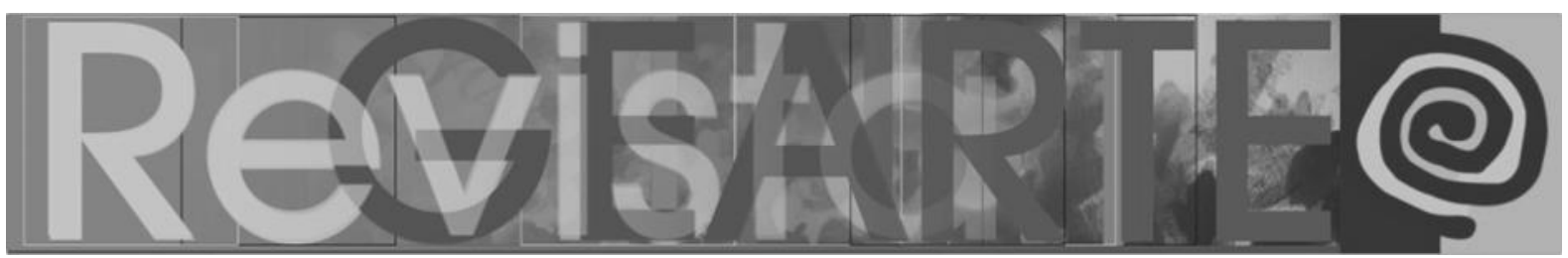

desde la complementariedad, que se puede desarrollar una creación transdisciplinar.

\section{Referencias}

AGUIRRE ARRIAGA, Imanol. Teorías y prácticas en la Educación Artística. España: Ed Octaedro, 2005.

AGUIRRE ARRIAGA, Imanol. Modelos formativos en educación artística: imaginando nuevas presencias para las artes en educación. Universidad Pública de Navarra. Bogotá, jul. 2006. Disponible en: https://bitacoramaedar.files.wordpress.com/2013/08/imanol-aguirre-modelosformativos-en-e-artc3adstica.pdf. Acceso en: 26 feb. 2020.

ARNHEIM, Rudolf. Arte $y$ percepción visual. 1970. Disponible en: https://www.academia.edu/25284169/Arte_y_Persepci\%C3\%B3n_visual-_Rudolf_Arnheim Acceso en: 18 feb. 2020

BORGES, Jorge L. El jardín de senderos que se bifurcan. In: BORGES, Jorge L Ficciones. Bogotá/Colombia: Ed Oveja Negra, 1984. p.75-87.

COLOM, Antoni J. La (de)construcción del conocimiento pedagógico. Barcelona: Paidós, 2002.

DIAZ, Ester. Posmodernidad. Buenos Aires: Biblos, 2009.

DONDIS, Donis A. La sintaxis de la imagen: introducción al alfabeto visual. Barcelona: Gustavo Gili, 1976. Disponible en:

https://www.academia.edu/21436318/d._a._dondis-_sintaxis_de_la_imagen . Acceso en: 18 feb.2020.

EFLAND, Arthur. Una historia de la educación del arte: tendencias intelectuales y sociales en la enseñanza de las artes visuales. Barcelona: Paidós, 2002.

EFLAND, Arthur; FREEDMANN, Kerry; STUHR, Patricia. La educación en el arte posmoderno. Barcelona: Paidós, 2003.

ELIADE, Mircea. El mito del eterno retorno. Barcelona: Planeta,1984.

FREUD, Sigmund. El malestar en la cultura. In: Sigmund Freud. Obras completas. Argentina: Amorrortu, 1979.

GLEICK, James. Caos. La creación de una ciencia. Barcelona: Critica, 2012.

GUASCH, Ana María. Una historia cultural de la posmodernidad y del poscolonialismo: lo intercultural entre lo global y lo local. In: ARANGO, Diego; DOMÍNGUEZ, Javier; FERNÁNDEZ, Carlos. La crítica del arte: entre el multiculturalismo y la globalización. Medellín: Carrea, 2008. p. 49-65.

LUHMANN, Niklas. Teoría de la sociedad y pedagogía. Barcelona: Paidós, 1996.

LUHMANN, Niklas. Complejidad y modernidad: de la unidad a la diferencia. Madrid: Trotta, 1998.

LUHMANN, Niklas. La sociedad de la sociedad. México: Herder. 2007

MALDONADO, Carlos E. Complejidad: ciencia, pensamiento y aplicaciones. Bogotá: Ed Universidad Externado de Colombia, 2007

MALDONADO, Carlos. El paradigma de la complejidad en sus implicaciones para las ciencias sociales. Video. 2013. Primera parte. Disponible en: https://www.youtube.com/ watch?v=GoC_rE39tt4. Acceso en: 13 mar. 2017. 


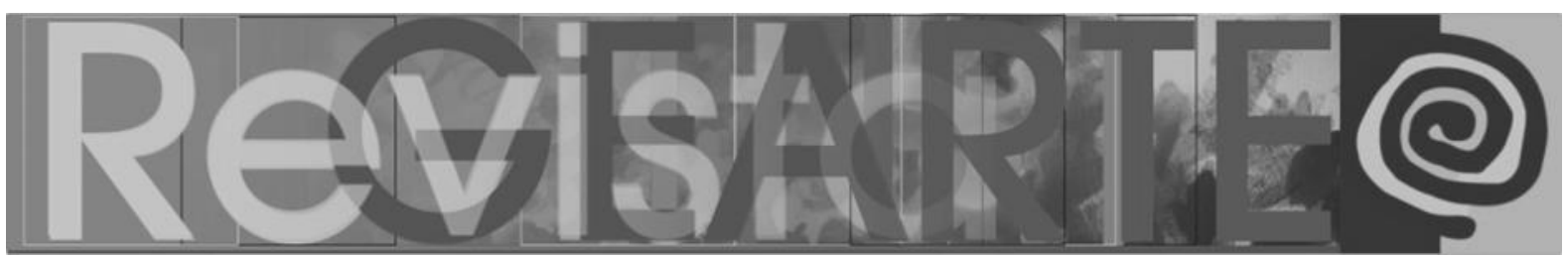

MALDONADO, Carlos. Significado e impacto social de las ciencias de la complejidad. Bogotá: Desde Abajo, 2015.

MASCAREÑO Aldo. Medios simbólicamente generalizados y el problema de la emergencia. Revista Cinta Moebio, n. 36. p.174-197, 2009. Disponible en: <https://cintademoebio. uchile.cl/index.php/CDM/article/view/18190/19061>_Acceso en: 26 feb. 2020.

MINISTERIO DE CULTURA DE COLOMBIA. Orientaciones pedagógicas para la educación artística en Básica y Media. Bogotá: Ministerio de Educación Nacional, 2010.

MORIN, Edgar. Sociología. Madrid: Tecnos,1995.

ORTIZ, John Mario; CARDONA, Bernardo Bustamante. Seminario taller Dibujo Experimental: Programa oficial del curso en el Departamento de Artes Visuales de la Facultad de Artes. Medellín: Universidad de Antioquia, 2013.

PRIGOGINE Ilya; STENGERS, Isabelle. La nueva alianza: metamorfosis de la ciencia. Madrid: Gallimard, 1997.

REGULES, Sergio. Las teorías del caos y la complejidad. España: Batiscafo, 2016.

SAMETBAND, José M. Entre el orden y el caos, la complejidad. México: Ed. Fondo de Cultura Económica, 1999.

WAGENSBERG, Jorge. Ideas sobre la complejidad del mundo. Barcelona: Tusquets, 1987.

\section{Bernardo Cardona Bustamante}

Docente em la Universidad de Antioquia, Medellín, Colombia. Master en Maestría en Educación en la Pontificia Universidad Javeriana (Colombia) y especialización en Pontificia Universidad Javeriana. Docente de intercambio en La Ecole Superieure d'Art de Lorient (Francia); Universidad Industrial de Santander (Colombia); Universidad Federal Minas Gerais (Brasil).

Orcid: https://orcid.org/0000-0002-4897-1944

E-mail: berbus00@hotmail.com

Currículo: http://lattes.cnpq.br/4422601153626244

Recebido em 28 de fevereiro de 2020

Aceito em 12 de maio de 2020 